EGU2020-8312

https://doi.org/10.5194/egusphere-egu2020-8312

EGU General Assembly 2020

(c) Author(s) 2020. This work is distributed under

the Creative Commons Attribution 4.0 License.

\title{
A synthesis of worldwide sediment source tracing research including fallout radiocesium (Cs-137)
}

\author{
Olivier Evrard ${ }^{1}$, Pierre-Alexis Chaboche ${ }^{1}$, Rafael Ramon ${ }^{1,2}$, Anthony Foucher ${ }^{1}$, and J. Patrick \\ Laceby $^{3}$ \\ ${ }^{1}$ CNRS-CEA, LSCE - Laboratoire des Sciences du Climat et de l'Environnement, Gif-sur-Yvette, France \\ (olivier.evrard@lsce.ipsl.fr) \\ ${ }^{2}$ Graduate Program in Soil Science, Federal University of Rio Grande do Sul, Porto Alegre, RS, Brazil \\ ${ }^{3}$ Environmental Monitoring and Science Division, Alberta Environment and Parks, Calgary, Alberta, Canada
}

Quantifying the main sources delivering harmful sediment loads to river systems is required to improve our knowledge of soil erosion processes. Among these potential sources, quantifying the contributions of surface (e.g. cultivated topsoil) and subsurface (e.g. channel bank, gully, landslide) material to sediment transiting river systems is of particular interest. Radiocesium $\left({ }^{137} \mathrm{Cs}\right)$ that was emitted during the atmospheric bomb tests that took mainly place in the 1960s and nuclear accidents provides an effective tracer to distinguish between topsoil material exposed to the fallout and subsoil sheltered from this fallout. A global synthesis of research articles $(n=123)$ that used radiocesium to fingerprint sediment sources indicated that the largest number of publications ( $55 \%$ of the total) were found in the United Kingdom, Australia and the United States. On the contrary, very few studies ( $9 \%$ of the total) were published for catchments located in Africa or South America. Given the low proportion of fallout recorded in regions located between $0-20^{\circ} \mathrm{N}$ and $0-20^{\circ} \mathrm{S}$, the potential of this technique for quantifying sediment source contributions may be limited in this part of the world. A similar conclusion may be drawn for applying this method in agricultural areas exposed to several soil erosion during the last several decades, such as Chinese Loess Plateau and South Africa. Overall, 94\% of studies incorporating ${ }^{137} \mathrm{Cs}$ as a potential tracer included this property in mixing models. In the future, given the continuous decay of the initial radiocesium fallout that peaked in the 1960s, the access to ultra-low background gamma-ray spectrometry facilities will be increasingly necessary to measure this important sediment tracing property. In addition, more research should be devoted to develop surrogate tracers providing discrimination between surface and subsurface material. Based on this extensive study review, researchers are also recommended to systematically include basic catchment information, details on the soil/sediment sampling design and access to raw data to facilitate the dissemination of this information among the communities of scientists and catchment managers. 